\title{
A EFETIVAÇÃO HORIZONTAL DOS DIREITOS HUMANOS: O \\ CIDADÃO E AS ONG'S, E NÃO SOMENTE O ESTADO, COMO \\ AGENTES SOCIAIS ATUANTES NA EFETIVAÇÃO DOS \\ DIREITOS DA CRIANÇA E DO ADOLESCENTE.
}

\author{
Aline Trein ${ }^{1}$ \\ Rafael Henrique Tiburski ${ }^{2}$ \\ Tiéli Zamperetti Donadel ${ }^{3}$
}

\begin{abstract}
RESUMO: Em uma sociedade cada vez mais preocupada com a busca e a efetivação de seus direitos, é imprescindível que se atente sobre o assunto com vistas a entendê-lo e a procurar difundi-lo de maneira a atingir aqueles que necessitam. Este trabalho busca a compreensão dos Direitos Humanos, focando no seu papel frente às Crianças e Adolescentes, e em como a sociedade e outras organizações nãogovernamentais podem torná-los mais presentes em nosso contexto atual.
\end{abstract}

PAlAVRAS-CHAVE: Direitos Humanos, Eficácia Horizontal, Educação, ONGs, Criança e Adolescente.

ABSTRACT: In a society increasingly preoccupied with the pursuit and realization of their rights, it is essential that consideration is given on the subject in order to understand it and seek to spread it so as to reach those in need. This work seeks to understand human rights, focusing on its role in front of Children and Adolescents, and how society and other non-governmental organizations may make them more present in our current context.

KEY-WORDS: Human Rights, Horizontal Efficacy, Education, ONGs, Children and Teenagers.

\section{INTRODUÇÃO}

Após o reconhecimento dos Direitos Individuais pelo Estado, que exigiam uma omissão do órgão estatal, as gerações de Direitos que se subseguiram demandaram, ao contrário, verdadeiras ações estatais, que são imprescindíveis para a efetivação dos Direitos Humanos.

O cenário atual, e brasileiro, evidencia uma incapacidade do Estado em atuar sozinho neste que é o seu papel de concretizador de Direitos e delega aos cidadãos, às organizações não-governamentais e demais entidades da sociedade a responsabilidade de complementar as políticas públicas que são desenvolvidas, e, na ausência delas, suprir suas lacunas.

A questão da criança e do adolescente é importante, principalmente, pela condição de ser humano em formação que, dada a precariedade das ações estatais, necessitam da atuação da sociedade e do cidadão para verem seus Direitos

\footnotetext{
${ }^{1}$ Acadêmica do Curso de Direito da Universidade Federal de Santa Maria/RS

${ }^{2}$ Acadêmico do Curso de Direito da Universidade Federal de Santa Maria/RS

${ }^{3}$ Acadêmica do Curso de Direito da Universidade Federal de Santa Maria/RS
} 
concretizados. E, mais do que contribuir para a concretização dos Direitos Humanos, a sociedade, o cidadão e as ONGs podem educar as crianças e adolescentes para que a noção de Direito Fundamental e de Direitos Humanos circule e se efetive horizontalmente, com a própria ação das pessoas, já conscientes de como colaborar para a efetivação desses direitos.

No Brasil, um país com muitas crianças e adolescentes em situação de vulnerabilidade social, e, muitas vezes ignorados pela sociedade, é mister tirar o manto da invisibilidade que paira sobre essa parte da população e reconhecer o outro (a criança abandonada, o adolescente que pede esmola, o abandonado que causa tumultos) como integrante da sociedade e, consequentemente, responsabilidade desta. A população, ao fechar os olhos, e vendar-se para a realidade fática, acaba por suscitar no outro, vítima de seu desprezo, o sentimento de não-pertencimento ao grupo social, delegando ao Estado a tarefa de "sumir" com tais crianças e adolescentes. Desta feita, resta ao cidadão, no exercício pleno de sua cidadania, e, engajado na efetivação dos direitos fundamentais da criança e do adolescente, reconhecer e suprir o abismo social que está entre ele e essas crianças.

\section{O CONCEITO DE DIREITOS HUMANOS}

É importante definir e conceituar o que sejam Direitos Humanos para "explicar e justificar as razões de seu reconhecimento e de sua exigência" (GORCZEVSKI, 2009, p. 47). Não há como sustentarmos a posição de necessidade e imprescindibilidade desses direitos e reclamar sua eficácia sem antes entendermos os requisitos, o contexto de surgimento e a sua classificação.

Ainda mais importante, no que toca à Criança e ao Adolescente, é explicitar que todos os direitos e garantias referentes à sua condição de ser humano em formação derivam do conceito lato sensu de Direitos Humanos. E que maior importância não há, do que aquela que diz respeito à salvaguarda dos direitos daqueles que serão sempre os próximos a assegurar os direitos dos que os precedem.

O conceito de Direitos Humanos não é pacífico na doutrina, suscitando diversas posições entre os autores que estudam o tema. O que parece ser consenso é de que esses Direitos não são mera concessão política, mas inerentes aos indivíduos. Eles figuram numa órbita superior à daquela das leis e costumes, subordinando-os aos seus princípios 
e postulados; representam as necessidades da pessoa humana, sem as quais, uma vida digna não pode se desenvolver. Nas palavras de Dallari,

Esses direitos são considerados fundamentais porque sem eles a pessoa humana não consegue existir ou não é capaz de se desenvolver e de participar plenamente da vida. Todos os seres humanos devem ter asseguradas, desde o nascimento, as condições mínimas necessárias para se tornarem úteis à humanidade, como também devem ter a possibilidade de receber os benefícios que a vida em sociedade pode proporcionar. (DALLARI, 2006, p.12)

Ainda, são "universais, porque exigíveis de qualquer autoridade política em qualquer lugar" (Gorczevski, 2009, p. 20). E derivam de um longo processo histórico, de lutas e conquistas, sem representar algo fortuito na história da humanidade ou imposto por uma autoridade política. Englobam os Direitos Individuais (princípio da liberdade), os Direitos Sociais (princípio da igualdade), e os Direitos Coletivos e Difusos (princípio da fraternidade).

Todos esses direitos correspondem às três gerações de Direitos Humanos (que para alguns autores já possui uma quarta e quinta gerações). Num primeiro momento, os direitos de liberdade apareceram como um contraponto ao Estado absolutista, exigindo uma omissão do Estado no que diz respeito a intervenções do poder público na esfera privada do indivíduo e na sua liberdade. Referem-se ao "direito à vida, a uma nacionalidade, à liberdade de movimento, liberdade religiosa, liberdade política, liberdade de opinião, o direito de asilo, à proibição de tortura ou tratamento cruel, desumano ou degradante, à proibição da escravidão, ao direito de propriedade, à inviolabilidade de domicílio etc." (GORCZEVSKI, 2009, p. 132-133).

Num segundo momento, os direitos sociais, econômicos e culturais, exigiram do Estado ações positivas, eis que "esses direitos só podem ser desfrutados com o auxílio do Estado, portanto se lhe impõe o dever de propiciar as necessárias condições" (GORCZEVSKI, 2009, p. 133). São os direitos relacionados ao trabalho, ao seguro social, à subsistência, ao amparo à doença e à velhice, ao direito à educação e cultura etc.

A terceira geração de direitos, nos dizeres de Goñi (2001 apud GORCZEVSKI, 2009, p. 136), diz respeito às novas circunstâncias atuais, que exigem que a titularidade dos direitos corresponda não mais ao ser humano isolado ou aos seres humanos em grupos, mas solidária e universalmente, a todos os homens. Esses direitos são aquelas de toda a coletividade humana: direito ao meio ambiente saudável, ao desenvolvimento 
sustentável, à qualidade de vida, ao desenvolvimento econômico, à paz entre as nações, à autodeterminação dos povos, à informação etc.

Uma quarta e quinta gerações diriam respeito aos avanços tecnológicos da humanidade, as mudanças no modo de viver, produzir e consumir, que criaram novos impasses que demandam novos direitos: reprodução assistida, eutanásia, clonagem, células-tronco, transgenia, inteligência artificial, realidade virtual etc. Mas, para a maioria da doutrina, esses novos direitos não passam de desdobramentos daqueles da terceira geração e que também dizem respeito à coletividade dos seres humanos.

Muito se perquire acerca da fundamentação teórica desses direitos, que não raro soa abstrata e é deixada de lado pelos pesquisadores da área. Duas são as principais correntes que tentam dar a base da teoria dos Direitos Humanos: a jusnaturalista e a positivista. A concepção jusnaturalista (Direito Natural, Jusnaturalismo Teológico e Jusnaturalismo Racional) comunga do entendimento de que "o fundamento não é jurídico e está fora do Estado" (GORCZEVSKI, 2009, p. 52). Ou seja, os Direitos Humanos nascem com o homem, são intrínsecos à sua natureza e vinculados à sua dignidade de pessoa humana; suas razões devem ser buscadas em matrizes ontológicas e metafísicas. Enquanto que a corrente positivista apresenta um fundamento desvinculado da moral e da ética e reduzido a um conjunto de normas jurídicas sem reconhecer o caráter extrajurídico dos Direitos Humanos.

Para não incorrer em uma discussão meramente acadêmica, o que importa ressaltar da fundamentação dos Direitos Humanos é que a corrente que mais parece se sustentar e foge mais facilmente ao livre arbítrio do poder e de uma possível vontade ilegítima de um legislador é a corrente jusnaturalista. E, assim coadunam os entendimentos dos diversos tratados internacionais acerca do tema, de um direito inato, universal, absoluto, necessário, inalienável, inviolável e imprescritível.

Ora, a aparente opção pela corrente jusnaturalista também não derroga a importância da positivação dos Direitos Humanos, seja para uma maior garantia e certeza desses direitos, seja para uma maior operacionalidade. Desse modo, é perceptível uma inclinação a um equilíbrio entre as duas correntes, muito bem expresso por Campos (1991, p.99) ao afirmar que "el derecho positivo debe 'positivar' como derechos humanos eso que, com tal nombre, tiene su fundamento 'fuera' de la positividad."

Não cabe aqui fazermos uma retomada histórica dos Direitos Humanos, sendo apenas importante ressaltar os diversos tratados internacionais que denotam uma nova 
posição dos Estados Democráticos de Direito contemporâneos e pós-segunda guerra mundial, no sentido de resguardarem aqueles que são os maiores bens que o Direito pode proteger: a vida e dignidade humanas.

Dentre os tratados, os principais são: a Declaração Universal dos Direitos Humanos de 1948, a Convenção Europeia dos Direitos Humanos de 1953, o Pacto de San José da Costa Rica de 1978, a Carta Africana dos Direitos Humanos e dos Povos de 1981, a Declaração Islâmica Universal dos Direitos Humanos de 1981 e a Carta Árabe dos Direitos Humanos de 1994.

No que tange à proteção e salvaguarda dos Direitos da Criança e do Adolescente, extremante importante é a Declaração Universal dos Direitos da Criança de 1959, adotada pela ONU. Eis o seu preâmbulo:

PROCLAMA esta Declaração dos Direitos da Criança, visando que a criança tenha uma infância feliz e possa gozar, em seu próprio benefício e no da sociedade, os direitos e as liberdades aqui enunciados e apela a que os pais, os homens e as melhores em sua qualidade de indivíduos, e as organizações voluntárias, as autoridades locais e os Governos nacionais reconheçam este direitos e se empenhem pela sua observância mediante medidas legislativas e de outra natureza, progressivamente instituídas, de conformidade com os seguintes princípios: (ONU, Assembléia Geral das Nações Unidas, 1959)

É composta de 10 princípios que visam assegurar os Direitos Fundamentais da Criança: como o direito a não discriminação, à proteção social, ao desenvolvimento físico, mental espiritual e social, a um nome e uma nacionalidade, à saúde, aos cuidados especiais (no caso das crianças portadoras de necessidades especiais), ao afeto, ao amor, à proteção da família, à educação etc.

Observamos que a Declaração Universal dos Direitos das Crianças soma-se à legislação pátria constitucional e ao Estatuto da Criança e do Adolescente no sentido de formar um todo extenso e farto que dá cabo de todas as necessidades básicas de uma criança e de um adolescente. Resta verificar especificamente no que a legislação constitucional e infraconstitucional brasileira complementa e reforça a Declaração e qual o grau de sua eficácia normativa no plano fático.

\subsection{Direitos Humanos no Brasil e sua Eficácia}

A introdução de uma legislação contemplativa dos Direitos Humanos no Brasil alcançou o máximo de expressão com a Constituição Brasileira de 1988. Acompanhando as tendências mundiais, e por que não, adiantando-se a elas, a Carta Brasileira de 1988 introduziu um novo marco na história do Brasil, quebrando um 
paradigma repressor e violador de direitos, simbolizado pelo Estado ditatorial que a precedeu. Ela se apresenta como a mais extensa, democrática e preocupada com a concretização dos Direitos Humanos e Fundamentais de toda a história do Brasil. E apesar das diversas críticas feitas ao diploma legal, a nova Carta foi entusiasticamente promulgada em 05 de outubro de 1988 por Ulisses Guimarães e chamada de "A Constituição Cidadã".

Os princípios norteadores desse diploma legal e que permeiam todo o seu texto e fazem dela referência para todos os Estados contemporâneos são resumidamente apresentados em seu preâmbulo:

\begin{abstract}
Nós, representantes do povo brasileiro, reunidos em Assembléia Nacional Constituinte para instituir um Estado Democrático, destinado a assegurar o exercício dos direitos sociais e individuais, a liberdade, a segurança, o bem-estar, o desenvolvimento, a igualdade e a justiça como valores supremos de uma sociedade fraterna, pluralista e sem preconceitos, fundada na harmonia social e comprometida, na ordem interna e internacional, com a solução pacífica das controvérsias, promulgamos, sob a proteção de Deus, a seguinte CONSTITUIÇÃO DA REPÚBLICA FEDERATIVA DO BRASIL. (BRASIL, Constituição da República Federativa do Brasil, 1988).
\end{abstract}

As intenções do Constituinte foram pioneiras na transição de um modelo e sistema que priorizava o arbítrio do poder e ignorava os anseios populares, contemplando, e garantindo em seu texto, todas as gerações de Direitos Humanos: os direitos individuais, elencados majoritariamente no Artigo $5^{\circ}$, Capítulo I, do Título II "Dos Direitos e Garantias Fundamentais"; os direitos sociais, que aparecem no Capítulo II, do Título I, do art. $6^{\circ}$ ao 11 (referentes ao trabalho), e no Título VIII - "Da Ordem Social", do art. 194 ao 232, que engloba os direitos referentes à Seguridade Social, à Saúde, à Previdência e Assistência Social, à Educação, Cultura e Desporto, à Ciência e Tecnologia, à Comunicação Social, ao Meio Ambiente, à Família, à Criança e ao Adolescente, ao Idoso e aos Índios; os direitos coletivos, retirados do art. $1^{\circ}$ e do art. $4^{\circ}$, no que tange aos princípios fundamentais que tratam da paz, da autodeterminação dos povos, do respeito aos direitos humanos, e especificamente, do Capítulo VI, do Título VIII, em seu artigo 225, que explicita o meio ambiente como um direito fundamental.

Importante ressaltar a inovação da emenda constitucional $\mathrm{n}^{\mathrm{o}} 45$ de 30 de dezembro de 2004, que traz no bojo de seu texto o status de emenda constitucional aos tratados internacionais sobre Direitos Humanos que o Brasil assinar e forem aprovados pelo Congresso Nacional. Observa-se aí, que além dos Direitos Fundamentais garantidos na Carta brasileira, o país tupiniquim ampliou ainda mais o seu rol de 
garantias ao abraçar todos os tratados em que é parte e os dando força de emenda constitucional, portanto, dotando-os da maior hierarquia legal possível.

Mas, por mais extensos que sejam os direitos garantidos na Constituição Brasileira (e fora dela), não é o grande número de artigos constantes de seu texto que garantirão a eficácia das normas ali prescritas. A verdadeira eficácia de uma norma reside na transposição dessa norma constitucional para o convívio da sociedade, buscando no seio social o respaldo necessário para sua concretização. Ora, já nos disse Miguel Reale (1995, p.113) em exímio ensinamento, que o "direito autêntico não é apenas declarado, mas reconhecido, é vivido pela sociedade, como algo que se incorpora e se integra na sua maneira de conduzir-se. A regra de direito deve, por conseguinte, ser formalmente válida e socialmente eficaz".

Tomando-se de referencial o campo dos Direitos da Criança e do Adolescente, portanto, Direitos Sociais, não é suficiente apenas a compatibilidade entre a norma e a realidade social. Além disso, para a concretização desses direitos é imprescindível a instituição de políticas públicas que forneçam o aparato necessário para que os mandamentos constitucionais possam efetivamente materializar-se. Todavia, o que ocorre no Brasil é um Estado que não despende os investimentos e recursos necessários, seja por desleixo político ou por outras situações, na estrutura fomentadora da eficácia normativa. Silva, já alertava para essa situação, pois,

\footnotetext{
Percebem-se, hoje, com maior precisão, os efeitos nefastos de uma filosofia minorista e de práticas públicas ineficientes desenvolvidas com base na doutrina da situação irregular vigente há décadas nesse país e profundamente arraigadas à cultura nacional. Aliando-se os aspectos culturais às características do Estado liberal brasileiro, pode-se afirmar que o atual quadro de degradação social, de violência, de desrespeito aos direitos fundamentais e de inércia cidadã está muito relacionada à incompetência desse próprio Estado capitalista moderno em cuidar, educar e desenvolver a sua infância e fundamentalmente, o feixe de direitos sociais de terceira geração que caracterizam o século XXI. (TRINDADE, 2005 apud SILVA, p.61)
}

E, é nessa lacuna estatal, que é chamada, em verdadeiro caráter de urgência, a figura da família e da sociedade para assegurar, ao lado das precárias políticas estatais, à criança e ao adolescente, todos os seus direitos fundamentais.

Quando o artigo 227 da Constituição Federal fala em "dever da família, da sociedade e do Estado em assegurar à criança e ao adolescente com absoluta prioridade," os direitos referentes à Criança e ao Adolescente, ele deixa clara a necessidade de uma verdadeira simbiose entre essas três instituições para a eficácia 
fática desses direitos. Sendo a contribuição estatal parca e fraca, acaba ricocheteando na família, na sociedade, e nas organizações não-governamentais o dever de agir.

\title{
2.2. A eficácia horizontal
}

A Eficácia de que aqui se trata difere em partes do conceito dado pela doutrina alemã para a Drittwirkung que tem seu fundamento na concretização dos Direitos Fundamentais no âmbito das relações privadas, como é elucidado por Dimitri Dinoulis e Leonardo Martins (2007),

\begin{abstract}
O reconhecimento do efeito horizontal parece ser necessário quando encontramos, entre os particulares em conflito, uma evidente desproporção de poder social. Uma grande empresa é juridicamente um sujeito de direito igual a qualquer um de seus empregados. Enquanto sujeito de direito, a empresa tem a liberdade de decidir unilateralmente sobre a rescisão contratual. $\mathrm{Na}$ realidade, a diferença em termos de poder social, ou seja, o desequilíbrio estrutural de forças entre as partes juridicamente iguais é tão grande que poderíamos tratar a parte forte como detentora de um poder semelhante ao do Estado. (DINOULIS; MARTINS, 2007)
\end{abstract}

A eficácia a que nos referimos é aquela que diz respeito à atuação da sociedade e de suas entidades representativas paralelamente às políticas públicas estatais na concretização dos Direitos Humanos e Fundamentais, por isso, também horizontal. Assemelha-se à eficácia nas relações privadas, que regula as conseqüências das disparidades entre as partes, mas, difere no seu campo de atuação: enquanto na Drittwirkung alemã a eficácia se dá no âmbito do indivíduo-indivíduo, a eficácia horizontal que fazemos referência ocorre entre o indivíduo-sociedade. Ela se estabelece nas relações, ou, nas ações dos indivíduos para efetivar direitos da coletividade e que dizem respeito a várias pessoas ou segmentos sociais. Como, por exemplo, as crianças e adolescentes em situação de vulnerabilidade social, tão carentes de uma maior presença de ONGs e grupos da sociedade que auxiliem as políticas públicas do Estado.

\section{DOS DIREITOS HUMANOS DA CRIANÇA E DO ADOLESCENTE}

O Estatuto da Criança e do Adolescente (Lei 8069/90) conceitua criança como aquela pessoa que tem até 12 anos de idade incompletos, e adolescente aquela compreendida entre os 12 e 18 anos de idade. No que se refere aos direitos dessas pessoas, não há dúvidas que nas últimas décadas houve um avanço em sua história e concretização. Três são os institutos que protegem os direitos da criança e do adolescente: a Convenção sobre os Direitos da Criança da ONU (1989), a Constituição Federal (1988) e o Estatuto da 
Criança e do Adolescente (1920). Até o surgimento desses institutos, existiram outras instituições voltadas ao acolhimento e à proteção desses indivíduos frágeis e muitas vezes vulneráveis. Primeiramente, surge no século XVIII a chamada Roda dos Expostos.

Eram normalmente instituídas por lei e vinculadas a Santa Casa de Misericórdia. Morcovo Filho relata em seus estudos que os primeiros hospitais de misericórdia foram construídos logo após a chegada de portugueses no Brasil, por volta de 1550. No entanto, a primeira Roda dos Expostos montada no Brasil foi em 1738. A partir de então, a Roda simbolizou um marco na filantropia-assistencialista nacional. Eram chamadas assim, porque se colocavam as crianças dentro de uma roda de madeira especialmente construída para esta finalidade. O mecanismo funcionava fico em um eixo, com uma abertura para a colocação de materiais, alimentos, vestimentas e doações em geral voltada para a rua. Não raras vezes eram deixadas crianças nas mais variadas condições. Ao girar a roda, a abertura voltava-se para dentro do prédio, sendo assegurado o anonimato daquele que efetuava o "depósito" pelo lado de fora. A primeira pessoa a ter contato como bebê ou os materiais era a porteira. (TRINDADE, 2005, apud SILVA, p.64)

Já perpassando o século XIX, alcançando o século XX, no período pós-primeira guerra aumentam as discussões acerca das questões sociais, da mão-de-obra infantil e da cidadania infantil, edita-se então o Código de Menores (1927).

\begin{abstract}
Sua utilização começa a ganhar força a partir da década de trinta, quando o Brasil inicia um processo de transformação social que provoca uma série de efeitos em diversas áreas do conhecimentos. É com o Estado Novo, após 1930, que se observa uma evolução nos direitos sociais e políticos. A Era Vargas inicia após um enfraquecimento acentuado da política café com leite do eixo São Paulo/Minas Gerais. O primeiro ato logo após a revolução de 30 foi a criação do Ministério do Trabalho. O populismo e o nacionalismo que marcaram a era Vargas buscavam preservar a raça com ordem e progresso da nação e do país. Foi a articulação entre o privado e o estatal (com o nascimento da LBA,por exemplo) que permitiu uma definição de política voltada ao menor, com uma ideologia definida e implementada com o apoio do Departamento Nacional da Criança. Conforme salienta Faleiros (1995, em Rizzini e Pilotti), é na Era Vargas que a política da infância, denominada "política do menor", articulando repressão, assistência e defesa da raça, vai ser tornar uma questão nacional, "e, nos moldes em que foi estruturada, vai ter uma longa duração e uma profunda influência nas trajetórias das crianças e adolescentes pobres do país (1995: 70)”. (TRINDADE, 2005 apud SILVA, p.68)
\end{abstract}

Em 1979 há a atualização do Código de 1927, promulgando o Novo Código de Menores e adequando aquela velha lei aos novos tempos. Já na década de 80 os princípios preconizados pela Convenção Internacional dos Direitos da Criança e do Adolescente são traduzidos nos seguintes artigos da Constituição Federal de 1988, art. 227 caput - É dever da família, da sociedade e do Estado assegurar à criança, ao adolescente e ao jovem, com absoluta prioridade, o direito à vida, à saúde, à alimentação, à educação, ao lazer, à profissionalização, à cultura, à dignidade, ao 
respeito, à liberdade e à convivência familiar e comunitária, além de colocá-los a salvo de toda forma de negligência, discriminação, exploração, violência, crueldade e opressão, e art. 228 - São penalmente inimputáveis os menores de dezoito anos, sujeitos às normas da legislação especial.

Em julho de 1990 surge, finalmente, o Estatuto da Criança e do Adolescente (Lei $\mathrm{n}^{\mathrm{o}}$.8.069), com o intuito de garantir e regular os princípios constitucionais e normas internacionais referentes a esses sujeitos. Entendidos como sujeitos portadores de direitos fundamentais e que devem ser preconizados com políticas de proteção integral.

\begin{abstract}
Desde a promulgação do ECA, um grande esforço para a sua implementação tem sido feito nos âmbitos governamental e não-governamental. A crescente participação do terceiro setor nas políticas sociais, fato que ocorre com evidência a partir de 1990, é particularmente forte na área da infância e da juventude. A constituição dos conselhos dos direitos, uma das diretrizes da política de atendimento apregoada na lei, determina que a formulação de políticas para a infância e a juventude deve vir de um grupo formado paritariamente por membros representantes de organizações da sociedade civil e membros representantes das instituições governamentais. (LORENZI, disponível em http://www.promenino.or.br)
\end{abstract}

Conscientes dessa necessária simbiose colaborativa entre as instituições governamentais e as organizações da sociedade civil na feitura das políticas referentes à infância e a juventude, trataremos agora, mais especificamente, do papel das ONGs.

\title{
04. A ATUAÇÃO DAS ONG's E O SEU PAPEL SOCIAL
}

Como já citado no capítulo anterior, desde sua criação, há um grande esforço para a implementação do Estatuto da Criança e do Adolescente, e não há dúvidas que as instituições não governamentais têm um forte papel de desempenho para a efetivação dos direitos garantidos nesse instituto. Nesse sentido, atitudes e ações praticadas pelas diversas ONG's que prestam assistência para as crianças e adolescentes que encontramse em situação de vulnerabilidade ou de risco merecem destaque.

ONG é a sigla para Organização Não-Governamental. A expressão aparece após a Segunda Guerra Mundial, sendo então utilizada pela primeira vez na Organização das Nações Unidas (ONU) para designar organizações supranacionais e internacionais que não foram estabelecidas por acordos governamentais. (CAMARGO. Disponível em http://www.institutojetro.com/Artigos/legislação_e_direito/ongs_esclarecimentos_essenciais.ht $\mathrm{ml})$ 
Chamado de Terceiro Setor, o conjunto de sociedades e associações sem fim lucrativos atuantes no país, dentre elas as ONGs, possuem uma legislação específica.

O Terceiro Setor é regulamentado, no Brasil, pela Lei 9.790/99, um primeiro passo na direção da regulamentação das relações entre Estado e Sociedade Civil no Brasil. Na prática, esta lei se propõe a distribuir o poder antes concentrado apenas no Estado, permitindo às populações, através de suas organizações, também influir nas decisões públicas e alavancar novos recursos ao processo de desenvolvimento do país. (BERNA. Disponível em http://www.escritorvilmarberna.com.br/artigos/cidadania-ambiental/o-terceirosetor.html)

Dentre os vários conjuntos de sociedade do terceiro setor empenhadas no atendimento de crianças carentes, foi pesquisada, na cidade de Santa Maria a ONG, Infância-ação, a qual possui um papel social importantíssimo na concretização de alguns direitos previsto no ECA.

\subsection{Ong infância-ação:}

Uma ação civil sem fins lucrativos, que nasceu da iniciativa e força de vontade de 03 jovens universitários da cidade de Santa Maria, foi regulamentada em fevereiro de 2007, com a missão de prestar assistência às crianças em situação de vulnerabilidade ou de risco, a fim de que todas tenham uma infância feliz, ou seja, com boas oportunidades referentes à educação, saúde, lazer, cultura e meio ambiente, promovendo a inclusão social das mesmas.

A ONG Infância-Ação atua de forma ampla na cidade, executando seus projetos nas dependências de escolas, instituições, centros comunitários e creches que necessitam de um apoio efetivo para atenderem suas crianças. Os locais de atuação são definidos mediante uma necessidade percebida através de visitas e indicações. Porém, uma das metas da organização é realizar um levantamento mais preciso com a implantação da Pesquisa de Opinião Pública (POP) nas vilas e instituições da cidade, a fim de reconhecer os locais que mais necessitam de auxílio e quais áreas devem contemplar o projeto em cada região de atuação.

Atualmente, a ONG está atuando e promovendo alguns projetos, debates e oficinas, dentre eles destacamos os seguintes projetos realizados, segundo dados fornecidos pelo relatório do ano de 2010 da ONG:

A Turma do Chiquinho: é um projeto que busca promover atividades diferenciadas para as crianças de 0 a 7 anos da Creche Estação dos Ventos, localizada no Km 3 na cidade de Santa Maria/RS. O projeto teve início em 28 de agosto de 2010, 
data que marca o primeiro encontro dos voluntários com as crianças, inaugurando assim as atividades. Tem como objetivo principal: Desenvolver a formação das crianças no âmbito psico-sócio-cultural de forma recreativa, suas capacidades e também ampliando seus conhecimentos, estabelecendo relações amigáveis entre si e na comunidade que estão inseridas e assim construindo para sua própria identidade. Esse projeto beneficiou um média 20 crianças no ano de 2010.

Projeto Clubinho de Línguas: é um projeto que busca promover atividades diferenciadas no ensino de língua estrangeira em escolas municipais da cidade de Santa Maria. O projeto teve seu início oficial no ano de 2008 atendendo 12 crianças da Escola Municipal de Ensino Fundamental Fontoura Ilha. Hoje, ele ocorre na EMEF Duque de Caxias, desde 11 de Agosto de 2010.

Projeto Escova-Ação: esse projeto tem como objetivo levar conhecimentos sobre a correta escovação dos dentes e da higiene bucal em geral, bem como, conscientizar às crianças e seus pais sobre a importância da saúde bucal. Ele foi idealizado e posto em prática no ano de 2008 atuando em cinco escolas da rede pública de ensino da cidade, atingindo cerca de 150 crianças.

Projeto Fazendo Rir: foi a primeira ação realizada pela ONG Infância-Ação. No início, apenas a Ala pediátrica do Hospital Universitário (HUSM) era atendida, após a ampliação do projeto a ONG também atende o CTCriac e a Turma do Ique. Além de levar alegria e diversão às crianças internadas, o projeto também proporciona aulas de Yoga às mães e familiares que acompanham as internações, acreditando que o bem estar dos acompanhantes reflete na recuperação e saúde dos pequenos. Beneficiou em média 20 crianças no ano de 2010.

\section{EDUCAÇÃO EM E PARA OS DIREITOS HUMANOS}

Diego não conhecia o mar.

O pai, Santiago Kovadlogg, levou-o para que descobrisse o mar. Viajaram para o Sul.

Ele, o mar, estava do outro lado das dunas altas, esperando. Quando o menino e o pai enfim alcançaram aquelas alturas de areia, depois de muito caminhar, o mar estava na frente de seus olhos.

E foi tanta a imensidão do mar, e tanto seu fulgor, que o menino ficou mudo de beleza.

E quando finalmente conseguiu falar, tremendo, gaguejando, pediu ao pai: 
A discussão sobre educação no contexto proposto por esse trabalho poderia ter dois focos distintos: um, sobre a educação em si, em ela como um direito fundamental; outro, sobre a educação em e para os direitos humanos.

Escolhendo a primeira alternativa, poderíamos expor o conceito de educação e as principais dificuldades encontradas nesse ínterim. Entretanto, gostaríamos de focar na segunda opção, e mostrar de que formas crianças e jovens podem se tornar agentes de mudança positiva da sociedade.

A educação em direitos humanos é uma prática recente em nosso país. É principalmente durante o contexto da transição democrática, após a ditadura militar, que ela começa a tomar relevância em nosso contexto social. Iniciou-se em meio à preocupação com a construção de uma cultura política, de uma cidadania ativa, de uma democracia participativa, e principalmente de uma afirmação dos direitos humanos.

É importante ter presente nesse sentido a promulgação de nossa Constituição, em 1988, considerada um marco na incorporação de direitos humanos de diversas gerações. Ainda, em 1990, foi aprovado e Estatuto da Criança e do Adolescente, demonstrando grande avanço em sistemas de proteção e garantia de direitos de crianças e adolescentes.

\begin{abstract}
Sendo assim, estamos diante de um quadro que ao mesmo tempo nos impulsiona e nos preocupa muito. Por um lado, percebe-se uma crescente visibilidade dos direitos humanos, impulsionada principalmente pela Declaração Universal e pela necessidade de reafirmar a sua validade enquanto um marco ético da humanidade para o novo milênio. Por outro, é inegável o grande contingente de pessoas que desconhecem seus próprios direitos de cidadania ou ainda não se deram conta da profundidade e da urgência de se discutir amplamente sobre os direitos humanos. (DE SOUZA, 2003, p.101).
\end{abstract}

A luta pela promoção dos direitos humanos situa-se em realidade de urgência: em uma sociedade marcada pela produção, pelo lucro e pelo consumo, a luta se transforma em um compromisso ético por aqueles que acreditam no valor da vida humana, no valor de sua dignidade.

E não se pode negar essa característica dos direitos humanos. Eles condensam os valores mais altos propagados pela sociedade, servindo como instrumento para legitimação da dignidade humana. E sabe-se que, apesar da ampliação que se teve em algumas décadas, a cidadania ainda não atinge a grande parcela da sociedade brasileira. O descompromisso com a educação é uma prova de tal informação. 
Assim, o comprometimento necessário com a educação vai além de reivindicar vagas em escolas e melhores salários para professores, é uma luta pelo respeito à dignidade humana.

Partimos da convicção de que a educação pode sim modificar a realidade no sentido de construir novos paradigmas, capazes de fortalecer a democracia, o exercício da cidadania e principalmente e efetivação dos direitos humanos.

O sentido da educação deve ser a formação da cultura da pessoa. E o fundamento das culturas deve ser os direitos humanos. Para isso, se torna imprescindível uma estrutura curricular preocupada em tais dimensões, para que tais direitos sejam interiorizados e posteriormente exteriorizados na forma de valores, comportamentos e ações.

$\mathrm{Na}$ escola, normalmente a preocupação gira em torno dos objetivos e conteúdos de caráter mais conceitual e racionalista. São temas desenvolvidos de maneira distante à realidade das crianças e dos adolescentes, longe de seus interesses e de sua realidade.

Assim, a educação em direitos humanos não deve limitar-se a introdução e reprodução de conhecimentos; em elaborar as metodologias necessárias, é importante ver as diversas dimensões englobadas pelos direitos humanos, e de que forma elas podem ser reconhecidas e aplicadas por crianças e adolescentes, em sua forma de ver, saber, celebrar, comprometer-se, socializar.

\footnotetext{
Nessa perspectiva, educar em direitos humanos supõe despertar a consciência e o sentimento da co-responsabilidade da vida em sociedade. Em seu dia-a-dia, a escola deve propiciar às crianças e jovens oportunidades de aprofundar a consciência de sua própria dignidade, a capacidade de reconhecer "o outro", de construir com as pessoas diferentes, favorecendo o diálogo intercultural através do reconhecimento dos diversos grupos sociais e culturais, da vivência da igualdade na diferença e da liberdade através da solidariedade e da partilha. (DE SOUZA, 2003)
}

Trazer à luz as contradições, analisar a realidade e propor alternativas destinadas a gerar mudanças são tarefas da educação em direitos humanos.

Um exemplo interessante aconteceu no Projeto Amanhecer, realizado por alguns jovens do Ensino Médio de uma escola particular do rio. Tais jovens iam regularmente a uma escola pública da favela da Rocinha, repassar seus conhecimentos e promover uma educação dos direitos humanos a crianças que iam a tal escola. 
É muito importante pra mim (sic) fazer essa experiência. Nas aulas com as crianças pude conhecer outro lado do Brasil, outra face que só conhecia pela televisão. Pude ver que os meios de comunicação não mostram realmente tudo que deveria ser mostrado. Ocultam a realidade e as pessoas não fazem nada para mudar isso. Além disso, o mais importante para mim foi que pude fazer amigos. Esses amigos são muito importantes para mim. Pude crescer e amadurecer por dentro. (Depoimento de um aluno do Ensino Médio participante do Projeto Amanhecer). (HORTA, 2003, p. 132).

Acreditamos que algumas estratégias podem ser utilizadas almejando incutir em crianças e jovens a consciência necessária sobre o tema dos Direitos Humanos:

1) Suscitar encontros da teoria com a realidade. Discutir, debater o ambiente percebido pelos alunos.

2) Abrir a perspectiva dos alunos, seu campo de conhecimento, propondo atividades multi-sensoriais que permitam a eles captarem as diversas dimensões que envolvem seus direitos.

3) Promover um trabalho educação da percepção, uma educação que desenvolva capacidades sensoriais e perceptivas, que desenvolvam uma curiosidade interessada e crítica diante do que acontece na realidade.

Para que possa ser transformada, é preciso que a realidade seja interiorizada nesses alunos, é preciso que haja uma conscientização da realidade.

Acreditamos, como Dallari, que:

Essa tarefa, do mais alto sentido humano e social, é um dever de todos, mas sobretudo dos educadores, daqueles que podem influir para a formação de novas mentalidades e para que não se reproduza, de geração para geração, a convicção de que as injustiças sao inevitáveis e de que é inútil lutar contra elas. divulgando a consciência dos direitos humanos, promovendo a preparação para o exercício da cidadania, os educadores estarão dando contribuição de extrema relevância para a criação de um mundo novo (...). divulgando os direitos humanos e preparando as gerações presentes e futuras para o exercício da cidadania os educadores estarão semeando a paz. (DALLARI, 2004, pg. 101)

O objetivo deste trabalho é propor uma análise da história com a realidade presenciada em nossa educação. Nosso contexto mostra a importância de uma educação formadora de jovens conscientes, capazes de lutar por seus direitos, quando já os conhecem. O que se deseja, em tempos de urgência, é a utopia da paz, de um cotidiano marcado pelo respeito aos meus e aos direitos do outro. É incerta ainda a efetividade concreta dessas práticas de conscientização e de interiorização de conhecimentos, mas sabe-se, ao menos, que trazem para mais perto o desejo de uma humanidade mais justa, não renunciando sua busca com vistas a um planeta mais habitável. 
Nessa perspectiva, a tarefa de educar em Direitos Humanos não se limita ao trabalho com indivíduos isolados que tomam consciência de seus problemas e tendem a procurar soluções para eles. O trabalho educacional abrange conjuntos de pessoas que coletivamente "se dão conta" do efeito multiplicador e do poder que a tomada de consciência coletiva adquire, bem como da solidariedade transindividual dos Direitos Humanos” (HORTA, 2003, pg. 138)

Nesse sentido, frisamos também o papel da eficácia horizontal dos direitos humanos. À partir da análise feita até agora, observamos que é um longo caminho a ser executado, e o papel dito dos educadores é de todos.

Conforme o pequeno texto aludido no início do capítulo, propagamos a ideia de abrir o horizonte de conhecimentos, de vontades, de sonhos e principalmente de realizações. Para isso, existe a necessidade do trabalho integrado, das ajudas mútuas. Um pai que consegue ajudar o filho a enxergar o mar é como cada partícula da sociedade que propicia um conhecimento a mais a outro alguém. São passos que para uns parecem pequenos, e que para outros são de extrema imensidão.

\section{CONSIDERAÇÕES FINAIS}

Neste trabalho, buscou-se uma maior compreensão em relação à abrangência dos Direitos Humanos. Procuramos expor os conceitos existentes e a forma com que eles podem ser efetivados a partir da atuação da sociedade, ou seja, sua efetivação horizontal. Dentro disso, demos foco ao objetivo da educação e da participação das ONGs no processo.

De tudo que foi apresentado até aqui, conclui-se que para a efetivação dos direitos humanos da criança e do adolescente é imprescindível além da atuação estatal, a atuação da sociedade. Verifica-se um aumento na preocupação por parte da sociedade, inclusive do Governo, nos últimos anos, em relação à participação de todos no exercício de suas cidadanias, e principalmente na proteção das crianças e adolescentes, em especial aqueles em situação de vulnerabilidade. Entretanto, ainda assim concluímos ser necessária a atuação de órgãos externos a esse, para que seus direitos sejam realmente protegidos e concretizados.

Reconhecemos, todavia, que a plena efetivação dos Direitos Humanos ainda está longe de ser concretizada, que ela demanda um processo programático e lento de 
conscientização, e que, apesar de ter suas bases teóricas fixadas ao longo dos últimos séculos, é para o futuro e no futuro que essa efetivação se dará integralmente. Pois, como bem diz Herkenhoff (1994, pg. 31), "reconhece-se que os Direitos Humanos não sedimentam a organização do Mundo, como está posto presentemente. Nesta perspectiva, os Direitos Humanos constituem uma utopia." Utopia essa que é combustível de luta para se alcançar um ideal: o de que todas as pessoas, além de terem seus direitos garantidos em uma carta constitucional, façam uso deles sem serem provocadas pelo Estado e possam sozinhas difundirem os valores ético-jurídicos e colocar em prática as noções de liberdade, igualdade, fraternidade e solidariedade tão festejadas pela humanidade.

A prática humanitária atual e o cuidado com as nossas crianças, reitera-se, serão as sementes dos tempos que virão, e a salvaguarda de que a humanidade poderá, eventualmente, abandonar o egoísmo em prol de um altruísmo desinteressado e engajado na promoção do bem comum.

\section{REFERÊNCIAS BIBLIOGRÁFICAS}

BERNA, Vilmar. O Terceiro Setor. Disponível em http://www.escritorvilmarberna.com.br/artigos/cidadania-ambiental/oterceirosetor.html. Acesso em 23 jun. 2011.

BRASIL. Constituição (1988). Constituição da República Federativa do Brasil. Brasília, DF: Senado Federal.

CAMARGO, Renato Barros Jr.. ONGs: esclarecimentos essenciais. Disponível em http://www.institutojetro.com/Artigos/legislaçao_e_direito/ongs_esclarecimentos_essen ciais.html. Acesso em 23 jun. 2011.

CAMPOS, Germán J. Bidart. Teoria General de los Derechos Humanos. Buenos Aires: Astrea, 1991.

CANDAU, Vera Maria. Educação em direitos humanos no Brasil: realidades e perspectivas. In: Educar em direitos humanos Construir democracia. Rio de Janeiro: DP\&A, 2003.

DA SILVA, Claudio Roberto Soares. A utopia da infância cidadã. In: Direito da Criança e do Adolescente uma abordagem multidisciplinar. Revista do Ministério 
Público do Rio Grande do Sul. Rio Grande do Sul, número 54, outubro/2004 a abril/2005.

DALlARI, Dalmo de Abreu. Direitos Humanos e Cidadania. $2^{\text {a }}$ Ed. São Paulo: Moderna, 2004.

DE SOUZA, Marcelo Gustavo Andrade. Direito à Educação: entre anúncios, denúncias e violações. In: Educar em direitos humanos Construir democracia. Rio de Janeiro: DP\&A, 2003.

DIMITRI, Dimoulis; MARTINS, Leonardo. Teoria Geral dos Direitos Fundamentais. São Paulo: Revista dos Tribunais, 2007.

GALEANO, Eduardo. O Livro dos Abraços. Tradução de Eric Nepomuceno. Porto Alegre: L\&PM, 2002.

GORCZEVSKI, Clovis. Direitos Humanos, Educação e Cidadania: conhecer, educar, praticar. $1^{\text {a }}$ Ed. Santa Cruz do Sul: EDUNISC, 2009.

HERKENHOFF, João Baptista. Curso de Direitos Humanos. São Paulo: Acadêmica, 1994.

HORTA, Maria del Mar Rubio. Educar em Direitos Humanos: compromisso com a vida. In: Educar em direitos humanos Construir democracia. Rio de Janeiro: DP\&A, 2003.

LORENZI, Gisella. Uma Breve História dos Direitos da Criança e do Adolescente no Brasil. Disponível em http://www.promenino.or.br/Ferramentas /Conteudo/tabid/77/ConteudoId/70d9fa8f-ad6c-4d8d-bb69-7d17278024b/Default.aspx. Acesso em 23 jun. 2011.

ONU. Declaração Universal dos Direitos do Homem. Assembleia Geral das Nações Unidas. Nova York: 1948

ONU. Declaração Universal dos Direitos da Criança. Assembleia Geral das Nações Unidas. Nova York: 1959

PICHLER, Rosimeri. Relatório ONG Infância Ação 2010.

REALE, Miguel. Lições Preliminares de Direito, 22 a ed., Ed. Saraiva, São Paulo, 1995.

SACAVINO, Susana. Educação em direitos humanos e democracia. In: Educar em direitos humanos Construir democracia. Rio de Janeiro: DP\&A, 2003. 